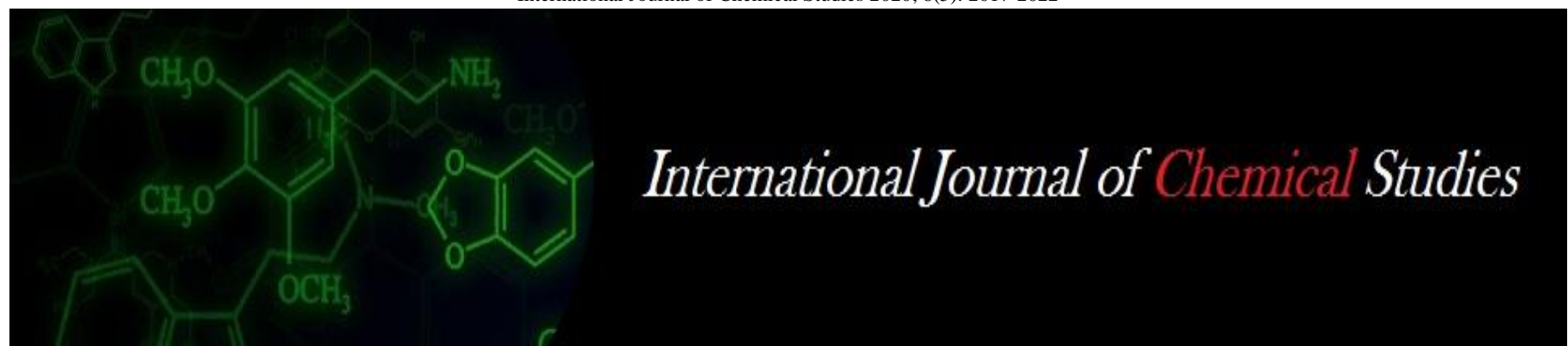

P-ISSN: 2349-8528

E-ISSN: 2321-4902

www.chemijournal.com

IJCS 2020; 8(5): 2017-2022

(C) 2020 IJCS

Received: 01-06-2020

Accepted: 06-07-2020

Sanjay Kumar Singh

Principal Scientist, Farm

Machinery \& Post Harvest

Technology Division, ICAR-

Indian Grassland \& Fodder

Research Institute, Jhansi, Uttar

Pradesh, India

Varshika Gangwar

Former M. Tech. Student,

Department of Agril Engg. \&

Food Tech, SVPUA\&T Meerut,

Uttar Pradesh, India

\section{Effect of temperature and concentration of osmotic solution on moisture loss and solid gain during osmotic dehydration of carrot}

\author{
Sanjay Kumar Singh and Varshika Gangwar
}

DOI: https://doi.org/10.22271/chemi.2020.v8.i5ab.10598

\begin{abstract}
The effect of temperature and osmotic solution concentration on solid gain and moisture loss drying characteristics of carrot were studied. The moisture loss and solid gain increased with increase in salt and sugar concentration and temperature. The moisture loss by carrot slices increased non-linearly with increase in duration of osmosis, solution concentrations and temperature. Mass transfer was faster in initial period of osmosis than the later period. Maximum moisture loss was obtained at $60{ }^{\circ} \mathrm{C}$ for osmotically dehydrated carrot (60\% sugar, $3 \%$ salt) and it ranged from $13.32 \%$ to $56.93 \%$. Solid gain increased with duration of osmosis and did not approach the equilibrium after $3 \mathrm{hrs}$ of osmotic dehydration. Solid gain at $60{ }^{\circ} \mathrm{C}$ solution temperature for osmotically dehydrated carrot $(60 \%$ sugar, $3 \%$ salt) ranged from $2.34 \%$ to $5.86 \%$. $60 \%$ sugar and $3 \%$ salt concentration with $60{ }^{\circ} \mathrm{C}$ solution temperature was found as an optimum process condition for osmosis with $3 \mathrm{~h}$ duration.
\end{abstract}

Keywords: Osmotic dehydration, solid gain, moisture loss, temperature, concentration

\section{Introduction}

Fruits and vegetables comprise of wide range of plant organs which are excellent sources of vitamins, minerals, fiber and carbohydrate. By proper selection, one can achieve a balance of nutrients even for those people who avoid animal sources of vitamins, minerals and carbohydrates. India is the second largest producer of vegetables in the world (ranks next to China) and accounts for about $15 \%$ of the world's production of vegetables. During 2017-18, area under vegetable cultivation in India was 10.26 million hectares with 184.40 million tonnes of production level (Horticultural Statistics at a Glance 2018) ${ }^{[5]}$. The process of impregnating the fruit in hypertonic syrup is called osmotic dehydration in which there is loss of water and gain of solute simultaneously. During the osmotic dehydration process partial dehydration and solute uptake occurs simultaneously. More water than solute usually transfers due to differential permeability of cellular membranes (Mauro and Menegalli 2003) [14]. Osmotic dehydration can be used as a pre-treatment for partial dehydration of fruits and vegetables. This technique also allows the incorporation of certain solutes, without modifying the integrity of the product. The removal of water from solid foods is a form of food conservation, inhibiting the growth of microorganisms, besides preventing a large part of biochemical reactions, which occur while the moisture is present (Park et al. 2002) ${ }^{[18]}$. The osmotic dehydration of fruits, meats and vegetables has been the aim of steady research attention during recent years as a useful method to improve the economics of dehydration processes.

Recently, osmotic dehydration process received more attention due to the consumer demand of minimally processed products. Carrot (Dancus carota L.) is cultivated in winter season throughout the world and is is rich in $\beta$ - carotene, a precursor of vitamin A, thiamine. Iron, vitamin C, lycopene, lutein and sugar (Mondhe et al. 2017 and Selvakumar et al. 2018) ${ }^{[15,22]}$. As it is seasonal and perishable in nature, it can be preserved by means of osmotic dehydration to extend its availability in off season (Sagar et al. 2010) ${ }^{[21]}$. The osmotic dehydration is also economical as compared to traditional drying method because high expenditure in case of conventional way of dehydration for fruits and vegetables (de Silva et al. 2013) ${ }^{[4]}$.
Corresponding Author: Varshika Gangwar Former M. Tech. Student, Department of Agril Engg. \& Food Tech, SVPUA\&T Meerut, Uttar Pradesh, India 
The use of osmotic dehydration process in the food industry has several advantages viz. quality improvement in terms of colour, flavour, texture, energy efficiency, packaging and distribution cost reduction, no chemical pretreatment, provide required product stability and retention of nutrients during storage (Salbani et al. 2002) ${ }^{[20]}$.

The rate of water loss and solids gain depends on several factors such as solution concentration, its temperature, contact time, level of agitation, sample size and geometry and solution/food ratio (Lerici et al. 1985) ${ }^{[13]}$. Solute choice and concentration depend on several factors, namely the effect on organoleptic quality properties, solute solubility, cell membrane permeability, its stabilizing effect and cost. The two most common solutes sugars and salts with relevance for sucrose and sodium chloride are used for osmotic treatment. Sugar is added to prevent the bleaching effect of salt (Jackson and Mohammed 1971) ${ }^{[8]}$. Previous workers have also pointed out the effectiveness in combining both solutes to obtain a maximum water loss with low solids gain by the product without significantly affecting product taste. Little information is available on systemic work of osmotic dehydration of carrots as influenced by process parameters. Therefore, an experiment was conducted to study the effect of temperature and osmotic solution concentration on solid gain and moisture loss during osmotic dehydration of carrot.

\section{Material and Methods \\ Sample preparation}

Fresh carrots procured from local market of Meerut, UP, were washed, graded and peeled followed by washing and slicing (10 mm thickness). Weighing of prepared samples of carrots were done and used for osmotic dehydration in binary mixture of sugar and salt solutions using solution to sample ratio 1:5. Fifty gram sample was taken with the help of electronic balance for osmosis and initial moisture content was determined for the same sample. Salt concentrations were chosen as 1, 2 and 3\% by weight. Sugar concentration was kept at 40, 50 and $60 \%$. Higher sugar concentration as recommended by (Islam and Flink 1982) [6] was not considered because preliminary trials in the present study indicated that this did not result in substantial advantage over $60 \%$ sugar concentration in respect of the extent of moisture loss related to the resultant sugar gain. Three levels of osmotic solution temperature $\left(40,50\right.$ and $\left.60^{\circ} \mathrm{C}\right)$ were considered with three replication of experiment.

\section{Osmotic Dehydration}

For each replication of an experiment, $50 \mathrm{gm}$ prepared sample immersed in $250 \mathrm{ml}$ osmotic solution was taken in $400 \mathrm{ml}$ beaker. Nine beakers were taken for taking sample for dehydration at $40{ }^{\circ} \mathrm{C}$ each having different sugar and salt solution for different time intervals $(0,15,30,45,60,90$, $120,150$ and $180 \mathrm{~min})$. Likewise, other samples were taken at $50{ }^{\circ} \mathrm{C}$ and $60{ }^{\circ} \mathrm{C}$. The temperature was maintained with the help of water bath. The sample solution was agitated to reduce the mass transfer resistance at the surface of the carrots and for good mixing and close temperature control in the osmotic medium. After each time interval of osmosis, samples were removed from the osmotic solution. During experimentation, it was assumed that the amount of solids (sugar, acids, minerals and vitamins) coming out of products enter into the medium as negligible. Although, these solids may be recognized as affecting the organoleptic and nutritional characteristics of the product. Osmotic dehydration was carried out from 0 to $180 \mathrm{~min}$ with varying time interval to investigate kinetics at each experimental condition. Five gram sample was taken from each sample for determination of moisture loss and solid gain. The moisture loss and solid gain were computed on the basis of mass balance.

\section{Determination of Process Parameters \\ Moisture content}

Moisture content was determined by hot air oven method recommended by Ranganna (2001) [19] for fruits and vegetables which had successfully been used for potato, carrot, etc. (Lenart and Flink 1984) ${ }^{[12]}$. Samples of 5 gm each were dried at $110{ }^{\circ} \mathrm{C}$ in oven for 16 to 18 hours. Weighing of sample was performed in petri plates by electronic balance of $0.0001 \mathrm{~g}$ accuracy and $150 \mathrm{gm}$ capacity. Hot air oven was thermostatically controlled with an accuracy of $\pm 1.0{ }^{\circ} \mathrm{C}$. Moisture content (MC) was calculated using following equation:

$$
\begin{aligned}
& \text { MC \% (w.b.) = weight of moisture / weight of the sample } \\
& \text { MC \% (w. b. })=\frac{\left(w+w_{1}\right)-w_{2}}{w} \times 100
\end{aligned}
$$

Where,

$\mathrm{W}=$ Net weight of sample taken, $\mathrm{g}$

$\mathrm{W}_{1}=$ Weight of the dish, $\mathrm{g}$

$\mathrm{W}_{2}=$ Weight of dish and oven dried sample, $\mathrm{g}$

\section{Moisture loss}

Based on review of earlier works (Lenart and Flink 1984) ${ }^{[12]}$, the moisture loss (percentage) was characterized using the following equation.

Moisture loss $(\%)=\frac{(\text { Weight of initial moisture }- \text { weight of final moisture })}{\text { Initial weight of sample }} \times 100$

\section{Solid gain}

The solid gain percentage was measured by the following equation as suggested by Lenart and Flink (1984) ${ }^{[12]}$.

Solid gain $(\%)=\frac{\text { (weight of final solid }- \text { weight of initial solid) }}{\text { Initial weight of sample }} \times 100$

\section{Statistical Analysis}

The experimental drying data were graphically analyzed in terms of moisture loss, and solid gain with drying time. The experimental data was analyzed with the help of spread sheet (EXCEL) software packages on personal computer. 


\section{Results and Discussion}

Effect of temperature and osmotic solution concentration on moisture loss during osmotic dehydration

Immersion in $40 \%$ sugar $+1 \%, 2 \%, 3 \%$ salt, $50 \%$ sugar + $1 \%, 2 \%, 3 \%$ salt and $60 \%$ sugar $+1 \%, 2 \%, 3 \%$ salt solution held at $40{ }^{\circ} \mathrm{C}$

The moisture loss by carrot during osmosis as calculated by mass balance is given in the Table 1. It was observed that the moisture loss from the sample when immersed in $40 \%$ sugar $+1 \%, 2 \%, 3 \%$ salt, $50 \%$ sugar $+1 \%, 2 \%, 3 \%$ salt and $60 \%$ sugar $+1 \%, 2 \%, 3 \%$ salt solution held at $40^{\circ} \mathrm{C}$ temperature for $0,15,30,45,60,90,120,150,180$ minutes respectively was found to be in range of $4.56-23.93$ for $40 \%$ sugar and $1 \%$ salt, 5.10- 24.90 for $40 \%$ sugar and $2 \%$ salt, 5.96- 26.35 for $40 \%$ sugar and 3\% salt, 6.25-32.69 for 50\% sugar and 1\% salt, 7.03-34.81 for 50\% sugar and 2\% salt, 7.66-36.23 for $50 \%$ sugar and 3\% salt, 8.11-43.31 for $60 \%$ sugar and $1 \%$ salt, 9.1- 45.12 for $60 \%$ sugar and $2 \%$ salt and 9.98- 46.23 percent for $60 \%$ sugar and $3 \%$ salt. The moisture loss by carrot slices increased non-linearly with duration of osmosis at all solution concentrations and the mass transfer was faster in initial period of osmosis than the later period. This is due to rise on fruit membrane permeability caused by higher temperatures which promotes swelling and plasticization of cell membrane, favouring mass transfer (Lazarides et al. 1995) ${ }^{[10]}$. Higher temperatures promote faster water loss through swelling and plasticizing of cell membranes as well as the better water transfer characteristics on the product surface due to lower viscosity of the osmotic medium (Lazarides et al. 1995) ${ }^{[10]}$. Thus, high temperature would release trapped air from the tissue resulting in more effective removal of water by osmotic pressure. It was observed form these data that the moisture loss increased nonlinearly with time (Table 1) and sugar salt solution concentration. A high initial rate of water removal followed by a slower removal in the later stages was observed. Several researchers observed similar trends for osmotic dehydration of foods (KaymakErtekin and Sultanoglu, 2000 and Park et al. 2002) ${ }^{[9,18]}$.

Table 1: Moisture loss during osmotic dehydration and different solution concentration of carrot slices at $40{ }^{\circ} \mathrm{C}$ temperature

\begin{tabular}{|c|c|c|c|c|c|c|c|c|c|}
\hline \begin{tabular}{|l|} 
Time \\
(min) \\
\end{tabular} & \begin{tabular}{|c|}
$40 \%$ sugar + \\
$1 \%$ salt \\
\end{tabular} & \begin{tabular}{|c|}
$40 \%$ sugar + \\
$2 \%$ salt \\
\end{tabular} & \begin{tabular}{|c|}
$40 \%$ sugar + \\
$3 \%$ salt \\
\end{tabular} & $\begin{array}{c}50 \% \text { sugar }+ \\
1 \% \text { salt } \\
\end{array}$ & $\begin{array}{c}50 \% \text { sugar }+ \\
2 \% \text { salt } \\
\end{array}$ & \begin{tabular}{|c|}
$50 \%$ sugar + \\
3\% salt \\
\end{tabular} & \begin{tabular}{|c|}
$60 \%$ sugar + \\
$1 \%$ salt \\
\end{tabular} & \begin{tabular}{|c|}
$60 \%$ sugar + \\
$2 \%$ salt \\
\end{tabular} & \begin{tabular}{|c|}
$60 \%$ sugar + \\
$3 \%$ salt \\
\end{tabular} \\
\hline 0 & 0.00 & 0.00 & 0.00 & 0.00 & 0.00 & 0.00 & 0.00 & 0.00 & 0.00 \\
\hline 15 & 4.56 & 5.10 & 5.96 & 6.25 & 7.03 & 7.66 & 8.11 & 9.10 & 9.98 \\
\hline 30 & 9.23 & 10.20 & 10.54 & 11.6 & 12.32 & 13.64 & 14.55 & 15.86 & 17.32 \\
\hline 45 & 12.89 & 13.45 & 14.69 & 16.16 & 17.26 & 18.62 & 20.84 & 22.32 & 24.27 \\
\hline 60 & 15.97 & 16.56 & 17.86 & 20.43 & 21.49 & 23.41 & 26.33 & 27.79 & 29.35 \\
\hline 90 & 18.89 & 19.36 & 20.83 & 23.68 & 25.57 & 27.54 & 31.06 & 32.82 & 34.54 \\
\hline 120 & 20.66 & 21.43 & 23.25 & 26.96 & 29.15 & 30.74 & 36.05 & 37.41 & 38.74 \\
\hline 150 & 22.33 & 23.52 & 24.89 & 29.97 & 32.21 & 33.64 & 40.08 & 41.69 & 42.98 \\
\hline 180 & 23.93 & 24.90 & 26.35 & 32.69 & 34.81 & 36.23 & 43.31 & 45.12 & 46.23 \\
\hline
\end{tabular}

Immersion in $40 \%$ sugar $+1 \%, 2 \%, 3 \%$ salt, $50 \%$ sugar $+1 \%, 2 \%, 3 \%$ salt and $60 \%$ sugar $+1 \%, 2 \%, 3 \%$ salt solution held at $50{ }^{\circ} \mathrm{C}$

The water loss by carrot slices during osmosis was measured by mass balance and is given in the Table 2 . It was observed that the moisture loss from the sample when immersed in $40 \%$ sugar $+1 \%, 2 \%, 3 \%$ salt, $50 \%$ sugar $+1 \%, 2 \%, 3 \%$ salt and $60 \%$ sugar $+1 \%, 2 \%, 3 \%$ salt solution held at $50{ }^{\circ} \mathrm{C}$ temperature for $0,15,30,45,60,90,120,150,180$ minutes respectively was found to be 5.56- 26.62 for $40 \%$ sugar and $1 \%$ salt, $6.05-29.63$ for $40 \%$ sugar and $2 \%$ salt, $7.1-32.82$ for $40 \%$ sugar and $3 \%$ salt, $8.12-37.52$ for $50 \%$ sugar and $1 \%$ salt, 9.00- 39.98 for $50 \%$ sugar and $2 \%$ salt, 9.66- 42.03 for $50 \%$ sugar and $3 \%$ salt, $10.01-45.94$ for $60 \%$ sugar $1 \%$ salt, 10.03-47.33 for $60 \%$ sugar and $2 \%$ salt and 11.0949.23 percent for $60 \%$ sugar and $3 \%$ salt. The moisture loss by carrot slices increased non-linearly with duration of osmosis at all solution concentrations and the mass transfer was faster in initial period of osmosis than the later period. A high initial rate of water removal followed by a slower removal in later stages was observed.

Table 2: Moisture loss during osmotic dehydration and different solution concentration of carrot slices at $50{ }^{\circ} \mathrm{C}$ temperature

\begin{tabular}{|c|c|c|c|c|c|c|c|c|c|}
\hline $\begin{array}{l}\text { Time } \\
(\min )\end{array}$ & \begin{tabular}{|c|}
$40 \%$ sugar + \\
$1 \%$ salt \\
\end{tabular} & \begin{tabular}{|c|}
$40 \%$ sugar + \\
$2 \%$ salt \\
\end{tabular} & \begin{tabular}{|c|}
$40 \%$ sugar + \\
$3 \%$ salt \\
\end{tabular} & $\begin{array}{c}50 \% \text { sugar }+ \\
1 \% \text { salt }\end{array}$ & \begin{tabular}{|c|}
$50 \%$ sugar + \\
$2 \%$ salt \\
\end{tabular} & \begin{tabular}{|c|}
$50 \%$ sugar + \\
3\% salt
\end{tabular} & $\begin{array}{c}60 \% \text { sugar }+ \\
1 \% \text { salt }\end{array}$ & \begin{tabular}{|c|}
$60 \%$ sugar + \\
$2 \%$ salt \\
\end{tabular} & $\begin{array}{c}60 \% \text { sugar }+ \\
\text { 3\% salt }\end{array}$ \\
\hline 0 & 0.00 & 0.00 & 0.00 & 0.00 & 0.00 & 0.00 & 0.00 & 0.00 & 0.00 \\
\hline 15 & 5.56 & 6.05 & 7.10 & 8.12 & 9.00 & 9.66 & 10.01 & 10.03 & 11.09 \\
\hline 30 & 9.23 & 10.23 & 11.3 & 12.89 & 14.24 & 15.58 & 16.52 & 17.52 & 18.32 \\
\hline 45 & 13.29 & 14.39 & 15.56 & 17.93 & 18.98 & 20.32 & 22.93 & 24.33 & 25.67 \\
\hline 60 & 16.47 & 17.98 & 19.56 & 22.35 & 23.81 & 25.51 & 29.3 & 30.53 & 32.53 \\
\hline 90 & 19.09 & 21.09 & 23.42 & 27.04 & 28.78 & 30.29 & 34.60 & 36.30 & 38.29 \\
\hline 120 & 21.56 & 24.00 & 26.90 & 31.00 & 33.24 & 35.14 & 39.2 & 40.86 & 43.04 \\
\hline 150 & 24.23 & 27.04 & 29.94 & 34.49 & 37.24 & 39.24 & 43.00 & 44.68 & 46.57 \\
\hline 180 & 26.62 & 29.63 & 32.82 & 37.52 & 39.98 & 42.03 & 45.94 & 47.33 & 49.23 \\
\hline
\end{tabular}

Immersion in $40 \%$ sugar $+1 \%, 2 \%, 3 \%$ salt, $50 \%$ sugar $+1 \%, 2 \%, 3 \%$ salt and $60 \%$ sugar $+1 \%, 2 \%, 3 \%$ salt solution held at $60^{\circ} \mathrm{C}$

From the obtained data as shown in Table 3, it was observed that the moisture loss from the sample when immersed in $40 \%$ sugar $+1 \%, 2 \%, 3 \%$ salt, $50 \%$ sugar $+1 \%, 2 \%, 3 \%$ salt and $60 \%$ sugar $+1 \%, 2 \%, 3 \%$ salt solution held at $60{ }^{\circ} \mathrm{C}$ temperature for $0,15,30,45,60,90,120,150,180$ minutes respectively was found to be 7.86-34.62 for $40 \%$ sugar and $1 \%$ salt, $8.56-39.01$ for $40 \%$ sugar and $2 \%$ salt, $9.01-41.82$ for $40 \%$ sugar and $3 \%$ salt, $10.22-45.55$ for $50 \%$ sugar and
$1 \%$ salt, $11.00-48.14$ for $50 \%$ sugar and $2 \%$ salt, 11.66- 50.03 for $50 \%$ sugar and 3\% salt, 12.36- 52.92 for $60 \%$ sugar and $1 \%$ salt, $12.93-54.89$ for $60 \%$ sugar and $2 \%$ salt and 13.32 56.93 percent for $60 \%$ sugar and $3 \%$ salt.

Overall from the above discussions, it was observed from the Tables 1 to 3, that the loisture loss increased with temperature and concentration of osmotic solution. 
Table 3: Moisture loss during osmotic dehydration and different solution concentration of carrot slices at $60{ }^{\circ} \mathrm{C}$ temperature

\begin{tabular}{|c|c|c|c|c|c|c|c|c|c|}
\hline $\begin{array}{l}\text { Time } \\
\text { (min) } \\
\end{array}$ & \begin{tabular}{|c|}
$40 \%$ sugar + \\
$1 \%$ salt \\
\end{tabular} & \begin{tabular}{|c|}
$40 \%$ sugar + \\
$2 \%$ salt \\
\end{tabular} & \begin{tabular}{|c|}
$40 \%$ sugar + \\
$3 \%$ salt \\
\end{tabular} & \begin{tabular}{|c|}
$50 \%$ sugar + \\
$1 \%$ salt \\
\end{tabular} & \begin{tabular}{|c|}
$50 \%$ sugar + \\
$2 \%$ salt \\
\end{tabular} & \begin{tabular}{|c|}
$50 \%$ sugar + \\
3\% salt \\
\end{tabular} & \begin{tabular}{|c|}
$60 \%$ sugar + \\
$1 \%$ salt \\
\end{tabular} & \begin{tabular}{|c|}
$60 \%$ sugar + \\
$2 \%$ salt \\
\end{tabular} & \begin{tabular}{|c|}
$60 \%$ sugar + \\
$3 \%$ salt \\
\end{tabular} \\
\hline 0 & 0.00 & 0.00 & 0.00 & 0.00 & 0.00 & 0.00 & 0.00 & 0.00 & 0.00 \\
\hline 15 & 7.86 & 8.56 & 9.01 & 10.22 & 11.00 & 11.66 & 12.36 & 12.93 & 13.32 \\
\hline 30 & 12.23 & 13.45 & 15.08 & 17.05 & 18.04 & 19.58 & 20.23 & 21.12 & 22.72 \\
\hline 45 & 17.29 & 19.00 & 20.56 & 23.65 & 25.38 & 27.32 & 28.54 & 29.01 & 30.67 \\
\hline 60 & 21.17 & 24.10 & 25.56 & 29.22 & 31.81 & 33.51 & 35.80 & 37.10 & 38.53 \\
\hline 90 & 25.00 & 28.50 & 30.42 & 34.36 & 36.68 & 38.39 & 41.85 & 43.69 & 45.29 \\
\hline 120 & 28.56 & 32.95 & 35.02 & 38.44 & 40.64 & 42.64 & 46.27 & 48.06 & 50.04 \\
\hline 150 & 31.83 & 36.21 & 38.94 & 42.40 & 44.64 & 46.84 & 49.82 & 51.98 & 53.57 \\
\hline 180 & 34.62 & 39.01 & 41.82 & 45.55 & 48.14 & 50.03 & 52.92 & 54.89 & 56.93 \\
\hline
\end{tabular}

Immersion in $40 \%$ sugar $+1 \%, 2 \%, 3 \%$ salt, $50 \%$ sugar $+1 \%, 2 \%, 3 \%$ salt and $60 \%$ sugar $+1 \%, 2 \%, 3 \%$ salt solution held at $40{ }^{\circ} \mathrm{C}$

\section{Effect of temperature and osmotic solution concentration on solid gain during osmotic dehydration}

The solid gain by carrot slices during osmosis was calculated by mass balance and is given in Table 4 . The solid gain during osmotic dehydration when immersed for $0,15,30,45$, $60,90,120,150,180$ minutes respectively was found to $0.55-$ 3.01 for $40 \%$ sugar and $1 \%$ salt, $0.80-3.28$ for $40 \%$ sugar and
$2 \%$ salt, $0.95-3.51$ for $40 \%$ sugar and $3 \%$ salt, $1.08-3.98$ for $50 \%$ sugar and $1 \%$ salt, $1.23-4.23$ for $50 \%$ sugar and $2 \%$ salt, 1.44-4.54 for 50\% sugar and 3\% salt, 1.60-4.86 for 60\% sugar and $1 \%$ salt, $1.80-5.21$ for $60 \%$ sugar and $2 \%$ salt and 2.00 5.46 percent for $60 \%$ sugar and $3 \%$ salt.. The solid gain by carrot slices during osmosis increased with increase in osmotic solution concentration.

Table 4: Solid gain during osmotic dehydration of carrot slices at $40^{\circ} \mathrm{C}$ temperature

\begin{tabular}{|c|c|c|c|c|c|c|c|c|c|}
\hline$\frac{\text { Time }}{(\text { min })}$ & \begin{tabular}{|c|}
$40 \%$ sugar + \\
$1 \%$ salt \\
\end{tabular} & \begin{tabular}{|c|}
$40 \%$ sugar + \\
$2 \%$ salt \\
\end{tabular} & \begin{tabular}{|c|}
$40 \%$ sugar + \\
$3 \%$ salt \\
\end{tabular} & $\begin{array}{c}50 \% \text { sugar }+ \\
1 \% \text { salt }\end{array}$ & \begin{tabular}{|c|}
$50 \%$ sugar + \\
$2 \%$ salt \\
\end{tabular} & $\begin{array}{c}50 \% \text { sugar }+ \\
\text { 3\% salt }\end{array}$ & $\begin{array}{c}60 \% \text { sugar }+ \\
1 \% \text { salt } \\
\end{array}$ & \begin{tabular}{|c|}
$60 \%$ sugar + \\
$2 \%$ salt \\
\end{tabular} & $\begin{array}{c}60 \% \text { sugar }+ \\
3 \% \text { salt }\end{array}$ \\
\hline 0 & 0.00 & 0.00 & 0.00 & 0.00 & 0.00 & 0.00 & 0.00 & 0.00 & 0.00 \\
\hline 15 & 0.55 & 0.80 & 0.95 & 1.08 & 1.23 & 1.44 & 1.60 & 1.80 & 2.00 \\
\hline 30 & 1.02 & 1.20 & 1.45 & 1.59 & 1.79 & 1.98 & 2.23 & 2.5 & 2.81 \\
\hline 45 & 1.42 & 1.65 & 1.89 & 2.08 & 2.26 & 2.48 & 2.80 & 3.10 & 3.38 \\
\hline 60 & 1.80 & 2.02 & 2.24 & 2.5 & 2.75 & 2.99 & 3.31 & 3.60 & 3.89 \\
\hline 90 & 2.16 & 2.38 & 2.62 & 2.96 & 3.18 & 3.43 & 3.78 & 4.10 & 4.36 \\
\hline 120 & 2.47 & 2.73 & 2.97 & 3.32 & 3.57 & 3.86 & 4.15 & 4.52 & 4.78 \\
\hline 150 & 2.78 & 3.00 & 3.28 & 3.68 & 3.92 & 4.21 & 4.53 & 4.85 & 5.12 \\
\hline 180 & 3.01 & 3.28 & 3.51 & 3.98 & 4.23 & 4.54 & 4.86 & 5.21 & 5.46 \\
\hline
\end{tabular}

Immersion in $40 \%$ sugar $+1 \%, 2 \%, 3 \%$ salt, $50 \%$ sugar $+1 \%, 2 \%, 3 \%$ salt and $60 \%$ sugar $+1 \%, 2 \%, 3 \%$ salt solution held at $50^{\circ} \mathrm{C}$

The results are tabulated in Table 5 . The solid gain during osmotic dehydration when immersed for $0,15,30,45,60,90$, $120,150,180$ minutes respectively was found was found to be 0.55-3.5 for $40 \%$ sugar and $1 \%$ salt, $0.65-3.97$ for $40 \%$ sugar and $2 \%$ salt, $0.83-4.32$ for $40 \%$ sugar and $3 \%$ salt, $1.00-4.82$ for $50 \%$ sugar and $1 \%$ salt, $1.19-5.13$ for $50 \%$ sugar and $2 \%$ salt, 1.34-5.47 for 50\% sugar and 3\% salt, 1.52-5.92 for $60 \%$ sugar and $1 \%$ salt, $1.70-6.24$ for $60 \%$ sugar and $2 \%$ salt and 1.94-6.51 percent for $60 \%$ sugar and $3 \%$ salt. The solid gain by carrot slices during osmosis increased with increase in osmotic solution concentration. The solid gain for $60 \%$ sugar and $3 \%$ salt at this temperature was found to be maximum.

Table 5: Solid gain during osmotic dehydration and different solution concentration of carrot slices at $50{ }^{\circ} \mathrm{C}$ temperature

\begin{tabular}{|c|c|c|c|c|c|c|c|c|c|}
\hline $\begin{array}{l}\text { Time } \\
(\min ) \\
\end{array}$ & \begin{tabular}{c|}
$40 \%$ sugar + \\
$1 \%$ salt \\
\end{tabular} & \begin{tabular}{|c|}
$40 \%$ sugar + \\
$2 \%$ salt \\
\end{tabular} & \begin{tabular}{|c|}
$40 \%$ sugar + \\
$3 \%$ salt \\
\end{tabular} & $\begin{array}{c}50 \% \text { sugar }+ \\
1 \% \text { salt }\end{array}$ & \begin{tabular}{|c|}
$50 \%$ sugar + \\
$2 \%$ salt \\
\end{tabular} & \begin{tabular}{|c|}
$50 \%$ sugar + \\
3\% salt \\
\end{tabular} & \begin{tabular}{|c|}
$60 \%$ sugar + \\
$1 \%$ salt \\
\end{tabular} & $\begin{array}{c}60 \% \text { sugar }+ \\
2 \% \text { salt } \\
\end{array}$ & \begin{tabular}{|c|}
$60 \%$ sugar + \\
$3 \%$ salt \\
\end{tabular} \\
\hline 0 & 0.00 & 0.00 & 0.00 & 0.00 & 0.00 & 0.00 & 0.00 & 0.00 & 0.00 \\
\hline 15 & 0.51 & 0.65 & 0.83 & 1 & 1.19 & 1.34 & 1.52 & 1.7 & 1.94 \\
\hline 30 & 0.98 & 1.19 & 1.38 & 1.58 & 1.89 & 2.12 & 2.3 & 2.58 & 2.81 \\
\hline 45 & 1.41 & 1.71 & 1.96 & 2.21 & 2.51 & 2.75 & 3 & 3.31 & 3.58 \\
\hline 60 & 1.87 & 2.19 & 2.49 & 2.85 & 3.21 & 3.48 & 3.75 & 3.98 & 4.31 \\
\hline 90 & 2.31 & 2.71 & 2.98 & 3.45 & 3.71 & 4 & 4.32 & 4.59 & 4.93 \\
\hline 120 & 2.67 & 3.21 & 3.48 & 3.88 & 4.23 & 4.53 & 4.89 & 5.24 & 5.51 \\
\hline 150 & 3.1 & 3.58 & 3.89 & 4.33 & 4.69 & 5 & 5.48 & 5.78 & 6.08 \\
\hline 180 & 3.5 & 3.97 & 4.32 & 4.82 & 5.13 & 5.47 & 5.92 & 6.24 & 6.51 \\
\hline
\end{tabular}

Immersion in $40 \%$ sugar $+1 \%, 2 \%, 3 \%$ salt, $50 \%$ sugar $+1 \%, 2 \%, 3 \%$ salt and $60 \%$ sugar $+1 \%, 2 \%, 3 \%$ salt solution held at $60{ }^{\circ} \mathrm{C}$

The total solid gain by carrot slices during osmosis was calculated by mass balance and is given in Table 6 . The solid gain during osmotic dehydration when immersed for 0,15 , $30,45,60,90,120,150,180$ minutes respectively was found to be $0.29-2.51$ for $40 \%$ sugar and $1 \%$ salt, $0.45-2.72$ for $40 \%$ sugar and $2 \%$ salt, $0.80-3.45$ for $40 \%$ sugar and $3 \%$ salt, 1.00 3.63 for $50 \%$ sugar and $1 \%$ salt, $1.09-4.01$ for $50 \%$ sugar and $2 \%$ salt, $1.23-4.60$ for $50 \%$ sugar and $3 \%$ salt, and $1.46-5.23$ for $60 \%$ sugar and $1 \%$ salt, $2.00-5.52$ for $60 \%$ sugar and $2 \%$ salt and 2.34-5.86 percent for $60 \%$ sugar and $3 \%$ salt. It was revealed that the solid gain increased with duration of osmosis and did not approach the equilibrium after 3 hour of osmotic dehydration it also increased with the concentration of the solution except few points. This was because of the increased concentration difference between carrot slices and solution. The solid gain also increased with increase in solution temperature. It may be due to collapse of the cell membrane at 
higher temperatures. Similar results have also been reported for peas and blueberries respectively.

In several studied, it has been concluded that cell membrane destruction at higher temperature lead to higher solid uptake by plant based materials during osmosis treatment (Tortoe et al. 2007 and Correa et al. 2010) [23, 3]. Previous research findings revealed higher amout of water loss and solid gain in more concentrated solution due to the greater osmotic pressure gradients (Ispir and Togrul 2009) [7]. In addition, increasing temperature caused a reduction on solution viscosity, lowering external resistance to mass transfer and resulted into easier water and solutes transport. Similar results were obtained by Mundada et al. 2011 [16] in osmotically dehydrated pomegranate arils. The experimental values for water loss and solid gain under different treatment conditions showed that water removal was always higher than the solid gain and it was in agreement with the results of other workers (Lenart 1996) $^{[11]}$.

\section{Standardization of optimum process condition of osmotic dehydration of carrots}

Results of our study indicates that the moisture loss was more in solution of $60 \%$ sugar and $3 \%$ salt with allowable solid gain at $60{ }^{\circ} \mathrm{C}$. However, greater solid gain can result in sucrose layers on carrot slices which further affect the product acceptability. This might be due the fact that salt molecule could diffuse more in the fruit tissue than sucrose molecule due to lower molecular weight, which was in close agreement with the results of Ade-Omowaye (2002) ${ }^{[1]}$ and Chang et al. (2003) ${ }^{[2]}$. The decrease in salt gain was the result of the possible formation of a concentration gradient around the fruit tissue by sucrose, which hindered the entrance of salt in to the product. The results were consistent with the findings of AdeOmowaye et al. (2002) ${ }^{[1]}$ and Ozen et al. (2002) ${ }^{[17]}$ for osmotic dehydration of red paprika and green pepper in sugarsalt mixture solution. Therefore, for acceptable quality, the solid gain in carrot slices should be less. The moisture loss at $5.86 \%$ solid gain was higher at $60 \%$ sugar and $3 \%$ salt concentration than salt concentrations at all temperature levels. Therefore, $60 \%$ sugar and $3 \%$ salt concentration with $60{ }^{\circ} \mathrm{C}$ solution temperature may be chosen as an optimum process condition for osmosis with $3 \mathrm{~h}$ duration. The higher temperatures at $60 \%$ sugar and $3 \%$ salt concentrations even require very less time for same moisture loss and solid gain but are not used because of energy requirement for heating osmotic solution as well as the disadvantage of quality deterioration of produce due to high temperature (Lenart and Flink 1984) ${ }^{[12]}$.

Table 6: Solid gain during osmotic dehydration and different solution concentration of carrot slices at $60{ }^{\circ} \mathrm{C}$ temperature

\begin{tabular}{|c|c|c|c|c|c|c|c|c|c|}
\hline \begin{tabular}{l|} 
Time \\
$(\min )$ \\
\end{tabular} & \begin{tabular}{|c|}
$40 \%$ sugar + \\
$1 \%$ salt \\
\end{tabular} & \begin{tabular}{|c|}
$40 \%$ sugar + \\
$2 \%$ salt \\
\end{tabular} & \begin{tabular}{|c|}
$40 \%$ sugar + \\
$3 \%$ salt \\
\end{tabular} & $\begin{array}{c}50 \% \text { sugar }+ \\
1 \% \text { salt }\end{array}$ & \begin{tabular}{|c|}
$50 \%$ sugar + \\
$\mathbf{2 \%}$ salt \\
\end{tabular} & \begin{tabular}{|c|}
$50 \%$ sugar + \\
3\% salt \\
\end{tabular} & \begin{tabular}{|c|}
$60 \%$ sugar + \\
$1 \%$ salt \\
\end{tabular} & $\begin{array}{c}60 \% \text { sugar }+ \\
2 \% \text { salt } \\
\end{array}$ & \begin{tabular}{|c|}
$60 \%$ sugar + \\
$3 \%$ salt \\
\end{tabular} \\
\hline 0 & 0.00 & 0.00 & 0.00 & 0.00 & 0.00 & 0.00 & 0.00 & 0.00 & 0.00 \\
\hline 15 & 0.29 & 0.45 & 0.80 & 1.00 & 1.09 & 1.23 & 1.46 & 2.00 & 2.34 \\
\hline 30 & 0.59 & 0.90 & 1.20 & 1.40 & 1.59 & 1.79 & 2.05 & 2.30 & 2.68 \\
\hline 45 & 1.01 & 1.30 & 1.45 & 1.78 & 1.89 & 2.32 & 2.64 & 2.87 & 3.01 \\
\hline 60 & 1.35 & 1.55 & 1.78 & 2.12 & 2.41 & 2.82 & 2.91 & 3.50 & 3.88 \\
\hline 90 & 1.65 & 1.85 & 2.21 & 2.46 & 2.68 & 3.25 & 3.63 & 3.87 & 4.03 \\
\hline 120 & 2.01 & 2.18 & 2.78 & 2.95 & 3.21 & 3.85 & 3.93 & 4.72 & 4.98 \\
\hline 150 & 2.23 & 2.47 & 3.02 & 3.30 & 3.61 & 4.21 & 4.71 & 5.02 & 5.42 \\
\hline 180 & 2.51 & 2.72 & 3.45 & 3.63 & 4.01 & 4.60 & 5.23 & 5.52 & 5.86 \\
\hline
\end{tabular}

\section{Conclusions}

Study revealed the following conclusions:

- The effect of temperature and osmotic solution concentration on moisture loss during osmotic dehydration revealed that the moisture loss by carrot slices increased non-linearly with increase in duration of osmosis, solution concentrations and temperature and mass transfer was faster in initial period of osmosis than the later period.

- Maximum moisture loss was obtained at $60{ }^{0} \mathrm{C}$ for osmotic dehydrated carrot of $60 \%$ sugar and $3 \%$ salt concentration and it ranged from $13.32 \%$ to $56.93 \%$.

- Solid gain increased with duration of osmosis and did not approach the equilibrium after 3 hour of osmotic dehydration. Solid gain at $60{ }^{\circ} \mathrm{C}$ solution temperature for osmotic dehydrated carrot of $60 \%$ sugar and $3 \%$ salt concentration ranged from $2.34 \%$ to $5.86 \%$.

- $60 \%$ sugar and $3 \%$ salt concentration with $60{ }^{\circ} \mathrm{C}$ solution temperature may be chosen as an optimum process condition for osmosis with $3 \mathrm{~h}$ duration.

\section{References}

1. Ade Omowaye BIO, Rastogi NK, Angersbach A, Knorr D. Osmotic dehydration behavior of red paprika (Capsicum annuum L.). J Food Sci. 2002; 67:179-196.

2. Chang MJ, Han MR, Kim MH. Effect of salt addition in sugar based osmotic dehydration on mass transfer and browning reaction of green pumpkin. Agric Chem Biotechnol. 2003; 46:92-96.

3. Correa JLG, Pereira LM, Vieira GS, Hubinger MD. Mass transfer kinetics of pulsed vacuum osmotic dehydration of guavas. J of Food Engg. 2010; 96(4):498-504.

4. da Silva WP, do Amaral DS, Duarte MEM, Mata ME, e Silva CM, Pinheiro RM. Description of the osmotic dehydration and convective drying of coconut (Cocos nucifera L.) pieces: a three-dimensional approach. $\mathbf{J}$ of Food Engg. 2013; 115(1):121-131.

5. Horticultural Statistics at a Glance. Horticulture Statistics Division, Department of Agriculture, Cooperation \& Farmers Welfare, Ministry of Agriculture \& Farmers Welfare, Govt. of India, 2018. www.agricoop.nic.in.

6. Islam MN, Flink JM. Dehydration of mango osmotic concentrations and its effect on air drying behavior. J Food Technol. 1982; 17:387-403.

7. Ispir A, Togrul TI. Osmotic dehydration of apricot: Kinetics and the effect of process parameters. Chemical Engg. Res. and Design. 2009; 87:166-180.

8. Jackson TH, Mohammed BB. The Shambat process: New development arising from the osmotic dehydration of fruits and vegetables. Sudan J Food Sci and Technol. 1971; 3:18-22.

9. Kaymak-Ertekin F, Sultanoglu M. Modeling of mass transfer during osmotic dehydration of apples. J of Food Engg. 2000; 46:243-250. 
10. Lazarides HN, Katsanidis E, Nickolaidis A. Mass transfer kinetics during osmotic pre-concentration aiming at minimal food uptake. J Food Engg. 1995; 25:151-166.

11. Lenart A, Cerkowniak M. Kinetics of convection drying of osmo-dehydrated apples. Polish J Food Nutrition Sci. 1996; 5:73-82.

12. Lenart A, Flink JM. Osmotic concentration of potato-I. Criteria for the end point of the osmosis process. J of Food Technol. 1984; 19:45-63.

13. Lerici CL, Pinnavaia G, Dalla Rosa M, Bartoluccci L. Osmotic dehydration fruit: Influence of osmotic agents on drying behavior and product quality. $\mathbf{J}$ of Food Sci. 1985; 50:1217-1219.

14. Mauro MA, Menegalli FC. Evaluation of water and sucrose diffusion coefficients in mango tissue during Osmotic concentration, J of Food Engg. 2003;57:367374.

15. Mondhe DS, Shinde SE, Deshmukh SS. Studies on osmotic dehydration of carrot slices. Iconic Res. and Engg J. 2017; 1(4):35-41.

16. Mundada M, Hathan BS, Maske S. Mass transfer kinetics during osmotic dehydration of pomegranate arils. $\mathbf{J}$ of Food Sci. 2011; 76:31-39.

17. Ozen BF, Dock LL, Ozdemir M, Floros JD. Processing factors affecting the osmotic dehydration of diced green peppers. International J Food Sci Technol. 2002; 37:497502.

18. Park KJ, Bin A, Brod FPR, Park THKB. Osmotic dehydration kinetics of pear D'anjou (Pyrus communis L.) J Food Engg. 2002; 52:293-98.

19. Ranganna S. Handbook of analysis and quality control of fruits and vegetable products. Tata McGraw Hill, New Delhi, 2001.

20. Sablani SS, Rahman MS, Al-Sadeiri DS. Equilibrium distribution data for osmotic drying of apple powder in sugar-water solution, J of Food Engg. 2002; 52:193-199.

21. Sagar V, Kumar PS. Recent advances in drying and dehydration of fruits and vegetables. J Food Sci. Technol. 2010; 47:15-26.

22. Selvakumar R, Tiwari RB. Physico-chemical changes in osmotically dehydrated carrot slices during storage. Int. J of Chemical Studies. 2018; 6(5):1685-1690.

23. Tortoe C, Orchard J, Beezer A. Osmotic dehydration kinetics of apple, banana and potato. Int. J of Food Sci. and Technol. 2007; 42:312-318. 